\title{
Pós-graduação multiprofissional em saúde: resultados de experiências utilizando metodologias ativas *
}

Maria José Sanches Marin ${ }^{1}$

Romeu Gomes ${ }^{2}$

Marilda Marques Luciano Marvulo ${ }^{3}$

Elisabete Medeiros Primo ${ }^{4}$

Pedro Marco Karan Barbosa ${ }^{5}$

Suelaine Druzian ${ }^{6}$

MARIN, M.J.S. et al. Multiprofessional health-related graduate courses: results from experiences using active methodologies. Interface - Comunic., Saude, Educ., v.14, n.33, p.331-44, abr./jun. 2010.

This study aimed to evaluate the results from an experience of multiprofessional health-related graduate courses based on active methodologies, from the viewpoint of its graduates. The methodological design consisted of an evaluative investigation that brought together quantitative and qualitative approaches. A structured questionnaire, semistructured interview and focus group were used as the data-gathering instruments. The quantitative treatment of the data consists in a frequency description, using the chisquare test and extension of Fisher's exact test. In qualitative terms, the method of sense interpretation based on hermeneutic and dialectic perspectives was used. Among the main results, the significant positive reaction to the course can be highlighted. Limits to the application of the results from the course to professional practice were also seen, mainly because of structural questions. It was concluded that use of active methodologies might contribute towards professional training at postgraduate level that is better aligned with the current national healthcare policies.

Keywords: Graduate in education. Evaluation. Active teaching-learning methodologies.
Este trabalho objetiva avaliar os resultados de uma experiência de pós-graduação multiprofissional em saúde ancorada em metodologias ativas, a partir da ótica de seus egressos. O desenho metodológico consiste numa pesquisa avaliativa que articula as abordagens quantitativa e qualitativa. Como instrumento de coleta de dados, trabalha-se com questionário estruturado, entrevista semiestruturada e grupo focal. O tratamento quantitativo dos dados consiste na descrição frequencial, utilização do Teste Quiquadrado e extensão do Teste Exato de Fisher. Em termos qualitativos, utilizou-se o método de interpretação de sentidos baseado nas perspectivas hermenêuticadialética. Dentre os principais resultados destaca-se a significativa positividade atribuída ao curso. Também foram constatados limites na aplicação dos resultados do curso na prática profissional, sobretudo por conta de questões estruturais. Conclui-se que a utilização de metodologias ativas pode contribuir para a formação profissional, em nível de pósgraduação, mais alinhada à atual política nacional de saúde.

Palavras-chave: Pós-graduação em Educação. Avaliação. Metodologias ativas de ensino-aprendizagem.

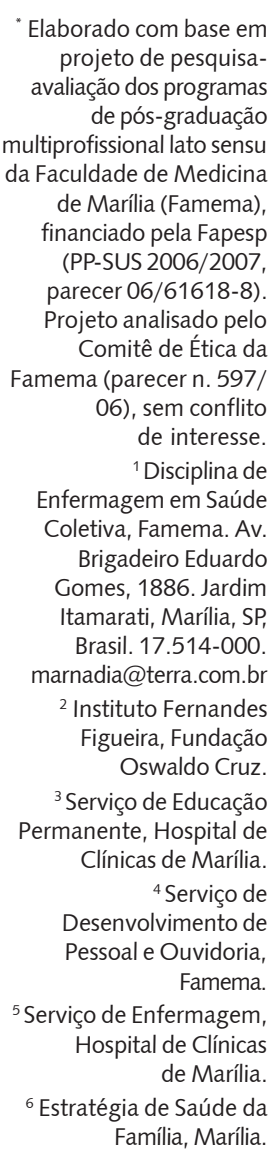




\section{Introdução}

Apesar de o Sistema Único de Saúde (SUS) ser amparado pela Constituição Federal e regulamentado por Leis, são grandes os obstáculos para sua consolidação, os quais se relacionam à necessidade de substituição de uma prática - que, por muitas décadas, foi arraigada nos aspectos curativos, na assistência hospitalar e na superespecialidade - por outra prática que valoriza a integralidade, o cuidado humanizado e a promoção da saúde. O principal indício de que será possível implantar um novo modelo de atenção está na formação profissional condizente com as novas necessidades das práticas em saúde (Merhy, Feuerwerker, Ceccim, 2006).

Por outro lado, Teixeira e Paim (1996) expressam que, embora a formação profissional seja condicionante dos serviços de saúde, este funciona como determinante da formação, o que implica a necessidade de mudanças no sistema de saúde e na concepção da sociedade, para que seja possível reorientar a formação.

Impõe-se, portanto, um grande desafio às instituições comprometidas com a formação de profissionais para a área da saúde, pois é preciso considerar que as ações de saúde se desenvolvem em cenários complexos e extremamente heterogêneos, e que devem ter como foco as necessidades de saúde da comunidade, e, como norte, a construção do SUS (Brasil, 1998).

$\mathrm{Na}$ busca de se favorecer a formação de sujeitos com visão ampliada de saúde, ativos e comprometidos com a transformação da realidade, considerando a complexidade que a caracteriza, fazse necessário introduzir novas formas de organizar e produzir o conhecimento, até então representado pela disciplinaridade, fragmentação do objeto e crescente especialização (Almeida Filho, 1997).

Neste contexto, o trabalho em equipe multiprofissional constitui uma importante ferramenta na abordagem das múltiplas dimensões que envolvem as ações de saúde, e o desafio é produzir um novo saber, oriundo dos processos de reflexão a respeito da complexa tarefa do cuidado às necessidades de saúde das pessoas, famílias e comunidade (Macedo, 2007).

O trabalho multiprofissional, na lógica da interdisciplinaridade, possibilita ampliar a capacidade humana de compreender a realidade e os problemas que nela se apresentam. Em se tratando do conhecimento que fundamenta as práticas dos profissionais da saúde, a interdisciplinaridade favorece a articulação do conhecimento de várias áreas com os seus saberes e os seus fazeres, de forma a dar mais sentido à teoria, ampliar a compreensão dos problemas de saúde e, consequentemente, melhorar a prática (Luck, 2000).

Em vista disso, nos últimos anos, uma série de iniciativas de formação pós-graduada, sobretudo na modalidade de Residência, vem sendo desenvolvida com o apoio de secretarias municipais, estaduais e do Ministério da Saúde. Um impulso significativo a tais iniciativas ocorreu por meio da Portaria Interministerial n.45/MEC/MS, de 12 de janeiro de 2007, que dispõe sobre a Residência Multiprofissional em Saúde e a Residência em Área Profissional da Saúde e institui a Comissão Nacional de Residência Multiprofissional em Saúde, permitindo assim que esses cursos sejam reconhecidos, credenciados e avaliados (Brasil, 2007).

Buscando atender a uma necessidade nacional, algumas instituições formadoras de profissionais de saúde vêm implementando cursos nessa modalidade e propondo mudanças curriculares e dos métodos de ensino/aprendizagem. A exemplo disso, cita-se a Faculdade de Medicina de Marília (Famema), estadualizada em 1994 como uma autarquia vinculada à Secretaria de Estado de Ensino Superior do Estado de São Paulo, que há mais de uma década vem desenvolvendo novas formas de ensino/ aprendizagem, visando à formação de um indivíduo crítico-reflexivo, capaz de trabalhar em equipe e de buscar o próprio conhecimento para atuar frente à diversidade e à complexidade que o cenário de prática profissional apresenta.

A partir de 2002, a Famema passou a desenvolver os cursos: Especialização Multiprofissional em Saúde da Família (ESF), Residência Multiprofissional em Saúde da Família (RSF) e Especialização integrada em Unidade de Terapia intensiva (UTI), tendo como características inovadoras o uso de metodologias ativas e o trabalho em equipe multiprofissional.

Considerando que os referidos cursos são desenvolvidos de acordo com novas propostas pedagógicas, que se destinam a formar profissionais em conformidade com as necessidades do SUS, o 
presente estudo pautou-se no conceito de metodologias ativas de aprendizagem, entendidas como um modelo de formação profissional mais condizente com os princípios da atual política de saúde.

Os métodos de aprendizagem ativa ancoram-se na pedagogia crítica. Essa corrente pedagógica ganha força nas décadas de 1970 e 1980, com a proposta da atividade escolar pautada na realidade social imediata, na qual se analisam os problemas e seus fatores determinantes e estrutura-se uma atuação com intenção de transformar a realidade social e política (Gadotti, 1998).

A teoria crítica, embora tenha sido originalmente usada pela escola de Frankfurt, na atualidade, abriga um amplo espectro de reflexões filosóficas com algumas diferenças em suas bases filosóficas (Tozoni-Reis, 2007). Apesar da diversidade apontada, afirma-se que essas correntes têm em comum: a ideia de que a escola é o local de se lidar com as contradições sociais e problematizar a realidade; a decisão do que saber e do que fazer está na dependência das necessidades sociais vividas; a superação da dicotomia "trabalho intelectual e trabalho manual"; a proposta de formar o homem pelo e para o trabalho (Aranha, 1989).

As chamadas metodologias ativas, no campo da formação profissional em saúde, vêm sendo embasadas em duas abordagens problematizadoras: Pedagogia da Problematização e Aprendizagem Baseada em Problemas. A primeira ancora-se nas concepções de Paulo Freire, que propõe a construção do conhecimento pelo movimento de agir sobre a realidade, uma vez que, no plano do pensamento, essa é refeita pela reflexão, a qual orienta o sujeito na transformação por meio da práxis (Novoa, 1981). A inserção crítica na realidade confere significado à aprendizagem. O eixo básico de orientação de todo processo refere-se à ação-reflexão-ação transformadora (Berbel, 1998).

Já na segunda, os estudantes - reunidos em pequenos grupos - são incentivados a utilizarem seus conhecimentos prévios na resolução de problemas selecionados para o estudo, visando: o desenvolvimento do raciocínio crítico, habilidades de comunicação e o entendimento da necessidade de aprender ao longo da vida (Barrows, Tamblyn, 1980).

Os métodos de aprendizagem ativa trabalham intencionalmente com problemas para o desenvolvimento dos processos de ensino-aprendizagem e valorizam o aprender a aprender (Berbel, 1998). A reflexão sobre as situações-problema desencadeia a busca de fatores explicativos e a proposição de solução ou soluções para o problema. Desta forma, problematizar significa ser capaz de responder ao conflito intrínseco que o problema traz (Zanotto, De Rose, 2003). Os conteúdos são construídos pelo estudante que precisa reorganizar o material, adaptando-o à sua estrutura cognitiva prévia, para descobrir relações, leis ou conceitos que precisará assimilar (Garcia Madruga, 1996).

Nessa ótica, o conhecimento é construído pelo movimento de agir sobre a realidade, uma vez que, no plano do pensamento, esta é refeita pela reflexão, a qual orienta o sujeito na sua transformação por meio da práxis (Nóvoa, 1981). Tal formulação aponta para o sentido da inserção crítica na realidade, para dela retirar os elementos que conferem significado em direção à aprendizagem (Cyrino, Toralles-Pereira, 2004). Nessa prática reflexiva, privilegia-se a aquisição ou domínio, in loco, de múltiplos aspectos que vão desde o método de trabalho ao processo intelectual dos que participam desse processo (Perrenoud, 1999a, 1999b).

A partir dessa perspectiva, neste estudo propõe-se avaliar os resultados de experiências de pós-graduação multiprofissional em saúde ancorada em metodologias ativas, com base na ótica de seus egressos.

\section{Metodologia}

O presente estudo é parte de uma investigação que se propôs a avaliar os cursos de Residência Multiprofissional em Saúde da Família (RSF), Especialização Multiprofissional em Saúde da Família (ESF) e Especialização Integrada em Terapia Intensiva (UTI), considerando as dimensões da qualidade: estrutura e gestão, processo e resultados alcançados; financiado pela Fapesp - Programa de Pesquisa para o SUS: gestão compartilhada em Saúde (PP-SUS 2006/2007).

Tal investigação pautou-se na pesquisa avaliativa e foram utilizadas as abordagens quantitativa e qualitativa, as quais são perspectivas complementares quando se pretende a aproximação de uma realidade com a finalidade de melhor conhecê-la (Minayo, Sanches, 1993). 
Na perspectiva da pesquisa avaliativa, neste estudo, focalizou-se a ótica dos egressos dos cursos RSF, ESF e UTI ofertados pela Famema, cursos que contam com apoio financeiro do Ministério da Saúde.

O curso de Especialização Multiprofissional em Saúde da Família (ESF) teve início no ano de 2002, sendo ofertado a cinco turmas, num total de 182 ingressantes e 174 concluintes. A Residência Multiprofissional em Saúde da Família, iniciada em 2003, contou com 57 ingressantes e cinquenta concluintes. A Especialização em UTI, iniciada em 2004, teve cinquenta ingressantes e 49 concluintes.

Quanto às categorias profissionais dos cursos estudados, salienta-se que o de UTI foi ofertado apenas para enfermeiros, nutricionistas e fisioterapeutas. O Curso ESF, por sua vez, foi ofertado para diferentes categorias profissionais da área da saúde, incluindo: médicos, enfermeiros, dentistas e fisioterapeutas, além de psicólogos e assistentes sociais. Às turmas ingressantes nos anos de 2002 e 2004, foi ofertado o curso de RSF, apenas para médicos e enfermeiros, cujos egressos constituíram-se nos sujeitos do estudo (Tabela 1).

Tabela 1. Distribuição das categorias profissionais dos concluintes dos cursos.

\begin{tabular}{|c|c|c|c|c|c|c|c|c|c|c|c|c|c|c|}
\hline \multirow{2}{*}{ Cursos } & \multicolumn{2}{|c|}{ Médico } & \multicolumn{2}{|c|}{ Enfermeiro } & \multicolumn{2}{|c|}{ Dentista } & \multicolumn{2}{|c|}{ Fisioterapeuta } & \multicolumn{2}{|c|}{ Nutricionista } & \multicolumn{2}{|c|}{ Outros } & \multicolumn{2}{|c|}{ Total } \\
\hline & $\mathrm{N}$ & $\%$ & $\mathrm{~N}$ & $\%$ & $\mathrm{~N}$ & $\%$ & $\mathrm{~N}$ & $\%$ & $\mathrm{~N}$ & $\%$ & $\mathrm{~N}$ & $\%$ & $N$ & $\%$ \\
\hline ESF & 67 & 38,5 & 75 & 43,1 & 19 & 10,9 & 4 & 2,3 & - & - & 9 & 5,2 & 174 & 100 \\
\hline RSF & 21 & 42 & 29 & 48 & - & - & - & - & - & - & - & - & 50 & 100 \\
\hline UTI & - & - & 34 & 69,4 & - & - & 8 & 16,3 & 7 & 14,3 & - & - & 49 & 100 \\
\hline Total $^{* *}$ & 88 & 32,2 & 138 & 50,5 & 19 & 6,9 & 12 & 4,4 & 7 & 2,6 & 9 & 3,3 & 273 & 100 \\
\hline
\end{tabular}

*Total de profissionais por curso; * ${ }^{*}$ Total de profissionais por categoria profissional.

A coleta de dados quantitativos deu-se nos meses de setembro a novembro de 2007, com a aplicação de um questionário estruturado, adaptado de uma proposta de avaliação de cursos de Saúde Pública Baseado (verificar) em Evidências, ministrados em países da América Latina (Almeida, 2006). Em tal questionário utiliza-se a escala de Likert, baseada no critério de ocorrência (sempre, quase sempre, muitas vezes, nunca, quase nunca, algumas vezes), na qual os egressos especificaram seu nível de concordância com a afirmação. Os questionários foram encaminhados para todos os egressos, via correio, juntamente com um envelope selado para facilitar a devolução.

Em relação à devolução dos questionários, levando-se em conta o total de egressos dos três cursos, o percentual de devolução de questionários respondidos (20,1\%) aproxima-se da média de $25 \%$ de devolução em situações de pesquisas organizacionais (Tabela 2) (Lakatos, Marconi, 1983). Mesmo assim, considera-se que este baixo retorno constitui um limite devido à representatividade numérica.

Tabela 2. Distribuição percentual dos egressos que responderam ao instrumento quantitativo, de acordo com os cursos.

\begin{tabular}{|c|c|c|c|c|}
\hline \multirow{2}{*}{ Cursos } & \multicolumn{2}{|c|}{ Egressos } & \multicolumn{2}{|c|}{ Responderam ao instrumento } \\
\hline & $\mathrm{N}$ & $\%$ & $\mathrm{~N}$ & $\%$ \\
\hline RSF & 50 & 18,4 & 12 & 4,3 \\
\hline ESF & 174 & 63,7 & 27 & 9,9 \\
\hline UTI & 49 & 17,9 & 16 & 5,8 \\
\hline Total & 273 & 100 & 55 & 20,1 \\
\hline
\end{tabular}


Os dados qualitativos foram coletados no mês de dezembro de 2007, por meio de entrevistas semiestruturadas, com 24 egressos, sendo oito de cada curso, por escolha aleatória, independente de ter respondido ou não ao instrumento estruturado. A quantidade de egressos pautou-se em princípios de amostra qualitativa (Minayo, 2006) que leva em conta o número de sujeitos em quantidade suficiente para que as questões da pesquisa sejam discutidas em profundidade, com a possibilidade de inclusões sucessivas de sujeitos, caso necessário. Nessa perspectiva, o quadro empírico se finaliza quando se observa a saturação de sentidos nas respostas dos entrevistados. Com base nesses princípios, esse número de egressos foi considerado suficiente.

$\mathrm{Na}$ análise dos dados qualitativos, em conformidade com os princípios da pesquisa avaliativa, considerou-se a necessidade de avançar para além da abordagem compreensiva desses, por meio da construção de indicadores que pudessem revelar o que se propunha avaliar. Trabalhou-se, então, com parâmetros de referência e com a construção dos indicadores, com base na ótica qualitativa (Assis, 2005), partindo-se das falas dos egressos e dos cursos que são objeto do presente estudo.

A partir da identificação dos indicadores qualitativos, formulados com base nas opiniões dos egressos sobre como deveria ser um curso de pós-graduação, os dados foram interpretados utilizando-se a perspectiva hermenêutico-dialética. Teve-se como referência os princípios do método de interpretação de sentidos, proposto por Gomes e colaboradores (Gomes et al., 2005), os quais se voltam para a interpretação do contexto, das razões e das lógicas da falas, das ações, correlacionando os dados ao conjunto de inter-relações e conjunturas, dentre outros corpos analíticos.

Caminhando nessa lógica, iniciou-se a leitura compreensiva dos depoimentos dos egressos dos três cursos, para identificação dos aspectos que, segundo os atores, representavam sua positividade, constituindo os indicadores de êxito. Tratase, portanto, da formulação de uma categoria-síntese, capaz de agregar, de forma sinérgica, os referenciais teóricos da análise. Nessa síntese, procurou-se também contemplar a perspectiva êmica, aqui entendida como a busca de padrões e regularidades na forma como são percebidos pelos próprios grupos estudados (Angrosino, 2009). Nesse sentido, a categoria-síntese expressa emicamente as vivências dos egressos durante o desenvolvimento do curso e dos resultados obtidos por eles na sua prática profissional.

Na sequência, por meio dos sentidos subjacentes às ideias descritas nas entrevistas, buscou-se identificar as regularidades e as vivências singulares. Por último, elaborou-se uma síntese interpretativa ancorada no confronto dos pontos de vista e das expressões das experiências dos atores. Nessa síntese, foram incorporadas, de forma crítica, as interpretações dos avaliadores sobre as falas produzidas pelos egressos, procurando trazer maior visibilidade aos limites e às possibilidades dos cursos.

${ }^{7} \mathrm{Na}$ avaliação positiva, foram agrupadas as categorias da escala Likert: "sempre", "quase sempre", "muitas vezes".

${ }^{8} \mathrm{Na}$ avaliação negativa, foram agrupadas as categorias da escala Likert: "nunca", "quase nunca" e "algumas vezes".
Os dados quantitativos foram digitados em planilhas do Excel 2000 for Windows para o adequado armazenamento das informações. As análises estatísticas foram realizadas com o software Statistical Package for Social Sciences (SPSS) versão 11.0 for Windows. As análises inferenciais empregadas com intuito de verificar a associação entre a avaliação (positiva ${ }^{7}$ ou negativa ${ }^{8}$ ) dos três cursos, no que se refere à opinião dos egressos quanto à qualificação para o trabalho em saúde e para o trabalho na área do curso, foram realizadas por meio do Teste de Qui-quadrado de Pearson e a extensão do Teste Exato de Fisher (Agresti, 1990). Em todas as conclusões obtidas pelas análises inferenciais foi utilizado o nível de significância $\alpha$ igual a $5 \%(p \leq 0,005)$. Os dados quantitativos foram apresentados 
PÓS-GRADUAÇÃO MULTIPROFISSIONAL EM SAÚDE: ...

em tabelas, constando os percentuais simples, sendo que a diferença para chegar aos $100 \%$ refere-se àqueles que não responderam ou não sabiam.

\section{Resultados}

\section{A avaliação, em números, dos resultados dos cursos}

A totalidade dos respondentes - quando questionada se os conhecimentos adquiridos durante o curso foram utilizados no seu cotidiano do trabalho - avaliou positivamente. Isso, no que se refere: à organização de ações de saúde, à socialização ou ao repasse das informações para a equipe; à evidenciação da necessidade de se efetuarem buscas ao se deparar com situações que exigem novos conhecimentos e dos meios pelos quais tais buscas devem ser realizadas. Dessa forma, pode-se inferir que os cursos estimularam mudanças efetivas de comportamento dos estudantes na sua prática profissional cotidiana, aspecto este enunciado no projeto pedagógico dos cursos que se propunham a imprimir uma nova lógica na atenção à saúde da população.

Embora a totalidade dos respondentes tenha emitido avaliação positiva para os diferentes aspectos, parece não ser possível fazer inferências para os cursos em geral, uma vez que eles constituem apenas $20 \%$ do total de egressos e, por isso, não representam necessariamente o conjunto dos egressos.

Os resultados também revelaram sua positividade na visão dos egressos respondentes, ao ser considerada a qualificação para o trabalho na área do curso (Tabela 3). Além disso, constatou-se não ter havido diferença estatisticamente significativa entre os cursos, exceto no quesito aperfeiçoamento contínuo $(p=0,046)$.

Tabela 3. Distribuição da avaliação (positiva ou negativa) feita pelos egressos quanto à qualificação para o trabalho em saúde, de acordo com o curso.

\begin{tabular}{|c|c|c|c|c|c|c|}
\hline \multirow{3}{*}{ DIMENSÃO } & \multicolumn{6}{|c|}{ CURSOS } \\
\hline & \multicolumn{2}{|c|}{$\operatorname{ESF}(n=27)$} & \multicolumn{2}{|c|}{$\operatorname{RSF}(n=12)$} & \multicolumn{2}{|c|}{ UTI $(n=16)$} \\
\hline & $\begin{array}{l}\text { Avaliação } \\
\text { positiva" }\end{array}$ & $\begin{array}{l}\text { Avaliação } \\
\text { negativa** }\end{array}$ & $\begin{array}{l}\text { Avaliação } \\
\text { positiva }\end{array}$ & $\begin{array}{c}\text { Avaliação } \\
\text { negativa }\end{array}$ & $\begin{array}{l}\text { Avaliação } \\
\text { positiva }\end{array}$ & $\begin{array}{l}\text { Avaliação } \\
\text { negativa }\end{array}$ \\
\hline $\begin{array}{l}\text { Utilização do conhecimento na } \\
\text { organização de ações de saúde }\end{array}$ & $100 \%$ & 0 & $100 \%$ & 0 & $100 \%$ & 0 \\
\hline $\begin{array}{l}\text { Socialização ou repasse do conhecimento } \\
\text { adquirido }\end{array}$ & $100 \%$ & 0 & $100 \%$ & 0 & $100 \%$ & 0 \\
\hline $\begin{array}{l}\text { Apreensão de como buscar novos } \\
\text { conhecimentos }\end{array}$ & $100 \%$ & 0 & $100 \%$ & 0 & $100 \%$ & 0 \\
\hline $\begin{array}{l}\text { Evidenciação da necessidade de novos } \\
\text { aprendizados }\end{array}$ & $100 \%$ & 0 & $100 \%$ & 0 & $100 \%$ & 0 \\
\hline
\end{tabular}

*Avaliação positiva abrange as frequências sempre, quase sempre, muitas vezes; * Avaliação negativa abrange as frequências nunca, quase nunca, algumas vezes.

É importante ressaltar que os cursos de RSF e UTI apresentaram a mesma porcentagem de avaliação positiva ( $p>0,999)$, ambas estatisticamente menores que a do curso ESF $(p=0,043)$.

Do ponto de vista quantitativo, os egressos respondentes consideram que os cursos possibilitaram o desenvolvimento de competências que incluem: o cuidado individual, o cuidado coletivo, a gestão e organização dos serviços de saúde, tal como proposto no projeto pedagógico deles. Nesse sentido, no que se refere à qualificação para o trabalho na área específica, pode-se considerar que os cursos obtiveram êxito na formação baseada em competência profissional, uma vez que refletem as tendências atuais de conceber o processo educativo a partir do aprender a ser, aprender a conhecer, aprender a fazer e aprender a conviver (Delors, 1998). 


\section{Avaliação qualitativa dos cursos pelos egressos}

$\mathrm{Na}$ avaliação qualitativa, ao se identificarem os referenciais de avaliação dos resultados dos cursos, constatou-se que, na ótica abstraída da fala dos egressos, o curso que utiliza metodologia ativa pode ser avaliado como exitoso quando proporciona integralidade, articulação teoria-prática, base para o trabalho em equipe e crescimento pessoal, conforme descritos no Quadro 1, com respectivos descritores e depoimentos ilustrativos.

Quadro 1. Referenciais de avaliação dos egressos (indicadores qualitativos).

\begin{tabular}{|c|c|c|}
\hline Indicadores & Descritores & Depoimentos ilustrativos \\
\hline Integralidade & $\begin{array}{l}\text { Percepção do todo, } \\
\text { envolvendo aspectos } \\
\text { individuais e coletivos; } \\
\text { ressignificação do PSF e do } \\
\text { SUS; inclusão da satisfação } \\
\text { do usuário na atenção à } \\
\text { saúde e domínio } \\
\text { contextualizado da teoria } \\
\text { e da técnica. }\end{array}$ & $\begin{array}{l}\text { "O curso me deu mais ferramentas para chegar à satisfação dos usuários } \\
\text { com mais facilidade" (E1ESF)."Era um trabalho em equipe, que não era } \\
\text { voltado para a patologia [...] era voltado para o trabalho no PSF, com o } \\
\text { trabalho do ACS [...] Acho que deu pra trabalhar bastante o individual, o } \\
\text { coletivo e a equipe" (E2-GF-ESF). } \\
\text { "[O curso me ajudou] a conhecer o Sistema Único de Saúde, aprofundar } \\
\text { mais como era esse programa [Saúde da Família]" (E2ESF). } \\
\text { "À medida que a gente aprende a trabalhar num ambiente complexo, } \\
\text { domina mais a técnica, domina mais a teoria, você entende mais o } \\
\text { contexto do usuário quanto também da própria família" (E5UTI). }\end{array}$ \\
\hline $\begin{array}{l}\text { Articulação } \\
\text { teórico-prática }\end{array}$ & $\begin{array}{l}\text { Base teórica para melhor } \\
\text { lidar com a prática, e } \\
\text { possibilitou a integração } \\
\text { teoria-prática, sem que } \\
\text { uma preceda a outra. }\end{array}$ & $\begin{array}{l}\text { "Para mim a aprendizagem complementou para atuar na prática, a parte } \\
\text { teórica [...] porque a parte teórica da especialização da saúde da família } \\
\text { é o que te empurra mesmo para você ter um estímulo para você atuar } \\
\text { na prática" (E2ESF). } \\
\text { "Eu via na prática e ia procurar, e isso me ajudou ate hoje [...] a procurar } \\
\text { até hoje" (E1-GF-UTI). }\end{array}$ \\
\hline $\begin{array}{l}\text { Bases para } \\
\text { o trabalho em } \\
\text { equipe }\end{array}$ & $\begin{array}{l}\text { Trabalho com diferentes } \\
\text { áreas de formação, } \\
\text { respeitando-as e } \\
\text { valorizando-as no trabalho } \\
\text { de equipe, bem como o } \\
\text { preparo para lidar com } \\
\text { conflitos que } \\
\text { eventualmente surjam por } \\
\text { conta da diversidade de } \\
\text { posicionamentos. }\end{array}$ & $\begin{array}{l}\text { "O curso contribuiu para lidar com os conflitos em equipe, a trabalhar } \\
\text { em equipe, perceber a dinâmica da equipe e aplicar isso" (E3RSF). } \\
\text { "[O curso contribuiu na minha relação com a equipe porque] a gente } \\
\text { aprende também que nem tudo são maravilhas, sempre vão existir } \\
\text { conflitos, dificuldades, e durante o curso a gente tem uma preparação } \\
\text { para isso através de planejamento de situações estratégicas, de } \\
\text { enfrentamento, uma série de coisas que são necessárias para a } \\
\text { organização do processo de trabalho" (E7RSF). } \\
\text { "[...] trabalhar em equipe, aprender a respeitar as profissões, também } \\
\text { considero que foi muito proveitoso" (E1RSF). } \\
\text { "Na minha turma era fisioterapia, nutrição e psicologia [...] eu hoje } \\
\text { consigo ver a importância [...] e consigo também ter alguns diagnósticos } \\
\text { que elas têm" (E4UTI). }\end{array}$ \\
\hline $\begin{array}{l}\text { Crescimento } \\
\text { pessoal }\end{array}$ & $\begin{array}{l}\text { Desenvolvimento pessoal, } \\
\text { o que resultar maior } \\
\text { segurança na atuação } \\
\text { profissional. }\end{array}$ & $\begin{array}{l}\text { "Acho que foi muito válido, você cresce como pessoa [...] a parte de } \\
\text { psicologia e psiquiatria a gente viu bastante" (E1ESF). } \\
\text { "Acho que a residência me trouxe tanto segurança como conhecimento } \\
\text { para eu atuar na área da forma como eu atuo hoje em dia" (E7RSF). }\end{array}$ \\
\hline
\end{tabular}

Nos depoimentos colhidos, os eixos que revelam o impacto dos cursos aproximam-se da proposta pedagógica destes, uma vez que um curso que utiliza metodologias ativas deve possibilitar aos egressos atuarem em conformidade com os princípios norteadores do SUS, envolvendo a integralidade e a articulação ensino-serviço. Além disso, deve incluir a base para o trabalho em equipe e o crescimento pessoal como aspectos a serem incorporados ao perfil dos profissionais capazes de imprimir uma nova lógica de atenção em saúde. 
Revela-se, assim, que o processo de aprendizagem se vincula à prática cotidiana dos serviços de saúde, propiciando a integração ensino/trabalho (Cyrino, Toralles-Pereira, 2004).

\section{Avaliação positiva dos resultados dos cursos}

Os egressos, em geral, constroem os seus depoimentos sobre os cursos no sentido de apontar êxitos alcançados a partir da formação que tiveram. A lógica que perpassa essa construção ancora-se nas dimensões cognitiva, afetiva e psicomotora. Em outras palavras, os egressos não se centram apenas em ganhos intelectuais obtidos no curso, mas destacam a articulação entre pensar, sentir e agir. Essa lógica, de certa forma, caminha no mesmo movimento da concepção que embasa as metodologias ativas, ou seja, abordar o sujeito do aprender dentro de uma perspectiva integral, o que se afina com os projetos pedagógicos dos cursos analisados no presente estudo.

Caminhando nesse raciocínio, os egressos avaliam positivamente os cursos por meio dos seguintes sentidos: o curso proporcionou uma sólida formação teórica e prática para a atuação profissional, um preparo para o trabalho em equipe e a visão dos princípios das políticas públicas de atenção à saúde.

Tais aspectos são condizentes com os fundamentos filosóficos e pedagógicos das metodologias ativas, pois contribuem para o enfrentamento das complexas e diversificadas situações do cotidiano dos serviços de saúde.

No que se refere à sólida formação teórica e prática atribuída ao resultado do curso, as ideias que se destacam são que a formação tanto caminhou na fundamentação teórico/científica e no saber conhecer como também capacitou a todos para um saber fazer eficiente e eficaz nas especialidades. A fundamentação científica dá o tom de profissionalismo e seriedade e o saber buscar conhecimentos alavanca o processo dando respostas à diversidade das demandas e às contínuas inovações nos saberes. A articulação entre saber e fazer, de certa forma, traz segurança para os egressos e consolida a graduação. Os depoimentos abaixo ilustram bem essas ideias:

"Então [o curso] me deu toda a base teórica e prática para o trabalho em Saúde da Família". (E2RSF)

“[...] uma melhor assistência por conta de uma fundamentação científica mais firmada [...]". (E8UTI)

"Acho que me ajudou porque eu comecei a ter mais facilidade para fazer buscas pela internet, aprendi a adquirir o conhecimento em relação à medicina baseada em evidência, que eu não conhecia". (E4RSF)

"Acho que nesse ponto a residência me trouxe tanto segurança como conhecimento para eu atuar na área da forma como eu atuo hoje em dia". (E7RSF)

Na concepção do projeto pedagógico dos cursos, uma sólida formação teórico-prática instrumentaliza os profissionais para a busca ativa do conhecimento e da constante atualização, visando o cuidado de acordo com as evidências da literatura. Agrega-se a tal instrumentalização a segurança nas intervenções, ou seja, o fazer profissional centrado na visão integral do usuário e nas relações interpessoais. A concepção dos cursos, portanto, revela grande aproximação com a ótica dos egressos.

Os egressos também atribuíram, como positividade do curso: o preparo para trabalhar em equipe, incluindo a compreensão do fazer/saber das diferentes categorias profissionais; a importância desse fazer/saber na qualidade do cuidado, e a capacidade de resolução dos conflitos no processo de trabalho, conforme expresso nas falas seguintes.

“[...] contribuiu assim para começar a despertar essa coisa da equipe, da troca de informações em benefício do paciente". (E2UTI) 
"A parte de gestão de trabalho, trabalhar em equipe, aprender a respeitar as profissões, também considero que foi muito proveitoso". (E1RSF)

O trabalho em equipe constitui estratégia do SUS para mudança do atual modelo de assistência em saúde, o qual se encontra fragmentado, com foco no biológico, centrado no médico e em medicações. Ele busca a democratização e a construção de trabalhadores e usuários cidadãos. As falas dos egressos, apontando esse aspecto como resultado dos cursos, indicam coerência com o que propõe o Sistema Único de Saúde e com os projetos político-pedagógicos dos cursos.

Acrescenta-se que o enfoque apontado pelos egressos vai ao encontro do conceito de interdisciplinaridade, que envolve um grupo de pessoas que recebam formação nos diferentes domínios do conhecimento (disciplinas), tendo cada um conceitos, métodos, dados e temas próprios. Os saberes e enfoques de outros profissionais funcionam de maneira a ampliar a visão dos egressos, revelando aspectos antes encobertos. Permite também uma abrangência maior de cuidados, à medida que clareia encaminhamentos e possibilita parcerias produtivas (Saupe, Budo, 2006).

De fato, esse tipo de prática só tende a alavancar o conhecimento, a visão do egresso, a comunicação entre os profissionais, a tomada de decisão e a gestão. Nessa lógica, os profissionais da saúde têm de entender que não bastam a si próprios. Existem outras competências que, se somadas, produzem um cuidado de melhor qualidade aos usuários. Esse resultado gera maior satisfação e motivação no trabalho.

A prática interdisciplinar é revestida de grande complexidade, por exigir dos profissionais nova forma de agir no seu cotidiano, além de implicar mudanças nas relações de poder entre os profissionais de saúde para que se amplie efetivamente a autonomia dos usuários e coletividades.

Pelos depoimentos, podemos perceber que, no geral, o curso deu sua contribuição para despertar, nos egressos, a necessidade de caminharem em busca dessa lógica, produzindo transformação no seu ambiente de trabalho. Isso está em consonância com os objetivos dos cursos.

Na ótica dos egressos, o curso lhes permitiu uma visão da política pública de atenção à saúde, por meio da compreensão dos princípios do SUS, destacando-se a ampliação do olhar ao considerarem as necessidades do usuário. As narrativas seguintes apontam esta visão:

"Acho que o curso ele faz com que a gente enxergue bem os princípios do SUS e que coloque os princípios em prática". (E4RSF)

"[...] você consegue ter um olhar mais ampliado, abranger tudo isso, o biopsicossocial". (E3RSF)

Esses aspectos revelados dão sentido ao fazer profissional, uma vez que proporcionam um agir na saúde com base em princípios e metas definidos, bem como, implicam a compreensão do processo saúde-doença, fundamental para as ações em saúde. Além disso, indicam que está havendo o enfrentamento de conhecimentos e valores cristalizados, hegemônicos, além de incluírem a construção de alternativas que ainda não são conhecidas (Feuerwerker, 2002).

Tomando por base o indicador ampliação do olhar, os resultados revelam que os egressos passaram a enxergar o usuário para além da doença e do seu corpo, aproximando-se da proposta de uma clínica ampliada. A clínica ampliada propõe uma transformação da atenção individual e coletiva, de forma a possibilitar que outros aspectos do Sujeito, que não apenas o biológico, possam ser compreendidos e trabalhados pelos profissionais de saúde (Cunha, 2005). Na clínica ampliada se lida com a singularidade de cada sujeito sem abrir mão da ontologia das doenças e suas possibilidades de diagnóstico e intervenção (Campos, Amaral, 2007). 


\section{Os limites percebidos nos resultados dos cursos}

$\mathrm{Na}$ busca para identificar, na fala dos egressos, os sentidos que apontam os resultados dos cursos na prática profissional, alguns limites foram destacados, relacionados tanto a fatores intrínsecos aos cursos realizados, como a limites externos a eles, ou seja, os limites do cotidiano dos serviços de saúde. Estes nem sempre propiciam que os resultados almejados pelos cursos se concretizem e se desenvolvam satisfatoriamente.

Entre os aspectos que os egressos consideram como limitantes para uma prática profissional em conformidade com as necessidades do SUS estão: as dificuldades de se implementarem ações voltadas para a coletividade; o excesso de demanda; a solicitação de cuidados voltados para a resolução da queixa principal, e as questões ligadas à gestão e à organização dos serviços de saúde. A dificuldade de se implementarem ações voltadas para a coletividade, na ótica dos egressos, deve-se tanto à pouca ênfase dada a esse aspecto durante o curso, como à forma de organização do serviço e à visão da população que busca, essencialmente, por cuidados individualizados. Ilustram tais dificuldades as narrativas abaixo:

"[Referindo-se às dificuldades] Às vezes no coletivo [...] eu tenho que parar de ver o individual que é a consulta, para chamar a população e envolver todo mundo. Alguns não gostam, eles acham fúteis, acham que a gente não está trabalhando, não conseguem enxergar a importância do trabalho coletivo". (E8RSF)

"Tem uma coisa que ficou falha no curso, que é a parte de planejamento em cuidados coletivos". (E1RSF)

"No coletivo a gente tem uma dificuldade muito grande [...] fala-se na prevenção e, na verdade, o que a gente faz é tentar remediar o curativo". (E7RSF)

"O coletivo eu tenho dificuldade dentro da instituição, acho que na rede básica é mais fácil enxergar o coletivo, aqui a gente acaba priorizando o individual, a dor no momento que o paciente está sentindo". (E4UTI)

Os egressos deixam entrever, em suas falas, que a excessiva demanda por consultas individualizadas na busca de resolver as queixas principais e a concepção de atenção à saúde presente no imaginário dos usuários dificultam um atendimento ampliado e voltado para a promoção da saúde, conforme exemplificado nas falas a seguir:

“[...] difícil principalmente quando a gente está com um monte de demanda que a pessoa quer que você dê conta dos problemas, de uma dor e ela não quer conversar com você, não quer informar se ela trabalha se não trabalha, se está bem em casa se não está, então muitas vezes realmente pula tudo isso aí e vai direto para a doença, só doença". (E8RSF)

"A gente quer realmente um dia atuar como uma unidade de saúde voltada pra prevenção, mas infelizmente hoje a gente está na parte curativa". (E7RSF)

"A correria do setor, né. A gente é responsável por 18 pacientes, 18 leitos e às vezes tem uma intercorrência e a gente não consegue fazer isso". (E4UTI)

Por fim, os contrapontos acabam se afunilando para questões que fogem da governabilidade dos egressos, mas que, sem dúvida, merecem o olhar reflexivo daqueles que podem atuar para favorecer melhores resultados na atuação dos profissionais da saúde. 


\begin{abstract}
"Tem coisas que fogem da governabilidade da gente [...]. Tem coisas que demandam política e isso não dá pra fazer. [...] recurso financeiro". (E4PSF)

"A gente tem muito limite, principalmente por parte de resolubilidade em gestão, a tentar resolver alguns problemas, tanto biológico como psicossocial, porque a gente está na ponta. Aí precisa de alguns recursos, precisa até de recursos humanos, recursos materiais, o que muitas vezes foge da nossa governabilidade, porque não somos nós que resolvemos, são nossos coordenadores". (E5PSF)
\end{abstract}

"A gente tem algum limite quando o hospital está numa condição mais difícil de verba, então às vezes a gente gostaria de entrar com uma dieta especial que o paciente precisa ou com um suplemento mais caro e o hospital não tem. Então, a gente tem esse limite também". (E3UTI)

Ao se considerarem os limites dos egressos na atuação profissional, percebe-se que apontam para o descompasso entre a formação dos novos profissionais e os princípios e diretrizes do SUS. Tal descompasso pode ser explicado pela excessiva fragmentação do processo de trabalho em diferentes dimensões, incluindo "a separação entre o pensar e o fazer; a fragmentação conceitual; a presença de profissionais especialistas; a fragmentação técnica e as rígidas relações de hierarquia e subordinação" (Haddad, Roschke, Davini, 1994, p.21).

No processo de mudanças, portanto, a identificação dos limites encontrados na prática profissional em especial na visão dos egressos que já foram sensibilizados para uma nova lógica de atenção em saúde - deve representar uma fortaleza na contínua busca de se imprimir uma nova lógica de atenção à saúde, visando à superação do paradigma que rege uma prática fragmentada e firmemente instalada tanto nas instituições de ensino como na prestação de serviços de saúde.

\title{
Considerações finais
}

O presente estudo apresenta, como limitação, a dificuldade de se generalizarem os achados, uma vez que o mesmo retrata a forma de utilização das metodologias ativas de uma única instituição; além disso, os dados quantitativos não correspondem ao universo dos egressos. Buscou-se, apesar desses limites, uma análise aprofundada acerca dos resultados dos cursos RSF, ESF e UTI, a partir da articulação das abordagens quantitativa e qualitativa. Enquanto a primeira apontou a significativa positividade dos cursos, a segunda não só possibilitou problematizar o que foi considerado positivo, como, também, melhor evidenciou os limites e os êxitos dos cursos.

Com base nos indicadores qualitativos sobre os resultados dos cursos que utilizaram metodologias ativas de aprendizagem, pode-se constatar que os egressos compreenderam, em grande parte, as dimensões que devem ser consideradas na formação de um novo profissional mais próximo dos princípios e diretrizes do SUS.

Além disso, observa-se que a lógica utilizada pelos egressos para avaliar positivamente os cursos, em geral, revelou a aplicação de princípios das metodologias ativas, uma vez que, para eles, foi possível uma visão ampliada e contextualizada da realidade, a articulação teoria-prática, além do desenvolvimento da capacidade de conviver com e respeitar os diferentes saberes necessários ao cuidado integral. A troca de experiência, o envolvimento com outras categorias profissionais, o aprender a trabalhar em grupo e o buscar o próprio conhecimento, de acordo com as necessidades do cotidiano, também se mostraram como reais aquisições dos cursos.

Tais resultados condizem com os achados de um ensaio teórico que, ao analisar as possíbilidades e os limites da $\mathrm{ABP}$ e da problematização, concluiu que estas modalidades de ensino podem representar um movimento inovador no contexto da educação na área da saúde, favorecendo as mudanças necessárias na implementação dos princípios do SUS (Cyrino, Toralles-Pereira, 2004). 
No entanto, o estudo também revelou que, ao se enfrentar o cotidiano dos serviços de saúde, ainda existe uma distância entre o que é preconizado e o que é realizado. Frente a esse limite percebido, indicam-se dois encaminhamentos. Um, relativo ao próprio método, é a necessidade de uma maior reflexão sobre os princípios da educação permanente, ao longo do curso, para que os egressos vejam a formação de pós-graduação como um processo que continuamente se constrói. Outro encaminhamento diz respeito a um maior investimento na área de competência de gestão e organização dos serviços de saúde, no processo do curso, para que os egressos possam lidar criticamente com os obstáculos que surgem por conta do distanciamento entre cotidiano e política de saúde.

Esta realidade reitera a importância de se continuar investindo no processo educativo, uma vez que ele possibilita o desencadeamento de reflexões sobre o fazer profissional no contexto do SUS, de forma que cada sujeito possa contribuir com propostas por meio de ações cotidianas, criativas e inovadoras.

É importante compreender que a atual organização dos serviços de saúde é resultante da construção de ações que se deu ao longo dos anos e que se encontra rigidamente estruturada, uma vez que, por muito tempo, conseguiu atender à necessidade de curar as doenças e de resolver a queixa principal.

A análise dos resultados referentes aos cursos de residência/especialização, aqui colocada, possibilitou constatar que é possível a incorporação das metodologias ativas de aprendizagem e a inclusão, no seu desenvolvimento, de profissionais das diferentes áreas de formação. Isto pode contribuir tanto no replanejamento desses cursos, quanto na implementação de outros que venham a ser estruturados para se alcançarem mudanças na formação profissional, iluminados por um novo olhar do processo ensino-aprendizagem.

\section{Colaboradores}

Maria José Sanches Marin coordenou o projeto e participou da justificativa, definição metodológica, análise dos dados e considerações finais. Romeu Gomes orientou a definição do referencial de análise, a análise dos dados e as considerações finais. Marilda Marques Luciano Marvulo, Elisabete Medeiros Primo, Pedro Marco Karan Barbosa e Suelaine Druzian participaram igualmente da definição metodológica, coleta de dados, análise dos dados e considerações finais.

\section{Referências}

ALMEIDA, C. Cursos de capacitação em saúde pública: protocolo de avaliação. Rio de Janeiro: Fiocruz, 2006.

ALMEIDA FILHO, N. Transdisciplinaridade e saúde coletiva. Cienc. Saude Colet., v.11, n.1/2, p.5-20, 1997.

ANGROSINO, M. Etnografia e observação participante. Porto Alegre: Artmed, 2009. (Coleção pesquisa qualitativa).

ARANHA, M.L.A. Filosofia da educação. São Paulo: Moderna, 1989.

AGRESTI, A. Categorical data analysis. New York: Wiley Interscience, 1990.

ASSIS, S.G. et al. Definição de objetivos e construção de indicadores visando à triangulação. In: MINAYO, M.C.S.; ASSIS, S.G.; SOUZA, E.R. (Orgs.). Avaliação por triangulação de métodos: abordagem de programas sociais. Rio de Janeiro: Fiocruz, 2005. p.105-32.

BARROWS, H.S.; TAMBLYN, R.M. Problem-based learning: an approach to medical education. New York: Springer, 1980. 
BERBEL, N.A.N. A problematização e a aprendizagem baseada em problemas: diferentes termos ou diferentes cominhos? Interface - Comunic., Saude, Educ., v.2, n.2, p.139-54, 1998.

BRASIL. Ministério da Educação. Portaria Interministerial n.45, de 12 de janeiro de 2007. Dispõe sobre a Residência Multiprofissional em Saúde e a Residência em Área Profissional da Saúde e institui a Comissão Nacional de Residência Multiprofissional em Saúde. Diário Oficial da União, Brasília, DF, 15 jan. 2007. Seção 1, p.28.

Ministério da Saúde. Secretaria de Assistência à Saúde. Coordenação de Saúde da comunidade. Saúde da Família: uma estratégia para a reorientação do modelo assistencial. Brasília: Ministério da Saúde, 1998.

CAMPOS, G.W.S.; AMARAL, M.A. A clínica ampliada e compartilhada, a gestão democrática e redes de atenção como referenciais teórico-operacionais para a reforma do hospital. Cienc. Saude Colet., v.12, n.4, p.849-59, 2007.

CYRINO, E.G.; TORALLES-PEREIRA, M.L. Trabalhando com estratégias de ensinoaprendizado por descoberta na área da saúde: a problematização e a aprendizagem baseada em problemas. Cad. Saude Publica, v.20, n.3, p.780-8, 2004.

CUNHA, G.T. A construção da clínica ampliada na atenção básica. São Paulo: Hucitec, 2005.

DELORS, J. Educação: um tesouro a descobrir: relatório para a Unesco da Comissão Internacional sobre Educação para o século XXI. São Paulo: Cortez, 1998.

FEUERWERKER L.C.M. Além do discurso de mudança na educação médica: processos e resultados - os casos de Marília e Londrina. São Paulo: Hucitec, 2002.

GADOTTI, M. Pedagogia da práxis. 2.ed. São Paulo: Cortez, 1998.

GARCIA MADRUGA, J.A. Aprendizagem pela descoberta frente à aprendizagem pela recepção: a teoria da aprendizagem verbal significativa. In: COLL, C.; PALÁCIOS, J.; MARCHESI, A. (Orgs.). Desenvolvimento psicológico e educação. Porto Alegre: Artmed, 1996. p.68-78.

GOMES, R. et al. Organização, processamento, análise e interpretação de dados: o desafio da triangulação. In: MINAYO, M.C.S.; ASSIS, S.G.; SOUZA, E.R. (Orgs.). Avaliação por triangulação de métodos: abordagem de programas sociais. Rio de Janeiro: Fiocruz, 2005. p.185-221.

HADDAD, Q.J.; ROSCHKE, M.A.C.; DAVINI, M.C. (Eds.). Educación permanente de personal de salud. Washington: OPAS, 1994.

LAKATOS, E.M.; MARCONI, M.A. Metodologia do trabalho científico. São Paulo: Atlas, 1983.

LÜCK, H. Pedagogia interdisciplinar: fundamentos teórico-metodológicos. 8.ed. Petrópolis: Vozes, 2000.

MACEDO, P.C.M. Desafios atuais no trabalho multiprofissional em saúde. Rev. SBPH, v.10, n.2, p.33-41, 2007.

MERHY, E.E.; FEUERWERKER, L.C.M.; CECCIM, R.B. Educación permanente en salud: una estrategia para intervenir en la micropolítica del trabajo en salud. Salud Colectiva, v.2, n.2, p.147-60, 2006.

MINAYO, M.C.S. Desafio do conhecimento. 9.ed. São Paulo: Hucitec, 2006.

MINAYO, M.C.S.; SANCHES, O. Qualitativo-quantitativo: oposição ou complementariedade? Cad. Saude Publica, v.9, n.3, p.239-48, 1993.

NOVOA, C.A.T. Leitura crítica de Paulo Freire. São Paulo: Loyola, 1981.

SAUPE, R.; BUDO, M.L.D. Pedagogia interdisciplinar: "educare" (educação e cuidado) como objeto fronteiriço em saúde. Texto Cont. Enferm., v.15, n.2, p.326-33, 2006. 
PERRENOUD, P. Formar professores em contextos sociais em mudança: prática reflexiva e participação crítica. Rev. Bras. Educ., n.12, p.5-21, 1999a.

Avaliação: da excelência à regulação das aprendizagens - entre duas lógicas. Porto Alegre: Artes Médicas do Sul, $1999 \mathrm{~b}$.

TEIXEIRA, C.F.; PAIM, J.S. Política de formação de recursos humanos em saúde: conjuntura atual e perspectivas. Divulg. Saude Debate, n.12, p.19-23, 1996.

TOZONI-REIS, M.F.C. Fundamentos teóricos para uma pedagogia crítica da educação ambiental: algumas contribuições. In: REUNIÃO ANUAL DA ANPED, 30., 2007,

Caxambú. Anais eletrônicos... Caxambu: Associação Nacional de Pós-Graduação e Pesquisa em Educação - ANPEd, 2007. Disponível em: <http://www.anped.org.br/ reunioes/30ra/trabalhos/GT22-3311-Res.pdf>. Acesso em: 19 jan. 2009.

ZANOTTO, M.A.C.; DE ROSE, T.M.S. Problematizar a própria realidade: análise de uma experiência de formação contínua. Educ. Pesqui., v.29, n.1, p.45-54, 2003.

MARIN, M.J.S. et al. Posgrado multi-profesional en salud: resultados de experiencias utilizando metodologías activas. Interface - Comunic., Saude, Educ., v.14, n.33, p.331-44, abr./jun. 2010.

El trabajo objetiva evaluar los resultados de una experiencia de posgrado multiprofesional en salud ancorada en metodologías activas a partir de la óptica de sus egresos. El diseño metodológico consiste en una investigación evaluativa que articula los planteamientos cuantitativos y cualitativos. Como instrumento de colecta de datos se trabaja con un cuestionario estructurado, entrevista semi-estructurada y grupo focal. El tratamiento cuantitativo de los datos consiste en la descripción frecuentativa, utilización del "Test Qui-Cuadrado" y extensión del "Test Exacto de Fisher". En términos cualitativos, se ha utilizado el método de interpretación de sentidos basado en las perspectiva hermenéutica-dialéctica. Entre los principales resultados se destaca la significativa positividad atribuida al curso. También se han constatado límites en la aplicación de los resultados en la práctica profesional, principalmente a causa de cuestiones estructurales. Se concluye que la utilización de metodologías activas puede contribuir para la formación profesional en nivel de posgrado, pero en línea con la actual política nacional de salud.

Palabras clave: Posgrado en educación. Evaluación. Metodologías activas de enseñanza-aprendizaje. 